\title{
O SISTEMA EDUCATIVO ANGOLANO E SUA ADEQUAÇÃO NO CONTEXTO CULTURAL DAS ZONAS RURAIS EM HUAMBO - ANGOLA (ÁFRICA)
}

\section{ARTIGO ORIGINAL}

CHILUMBO, Alcídio Edgar José ${ }^{1}$

CHILUMBO, Alcídio Edgar José. 0 sistema educativo angolano e sua adequação no contexto cultural das zonas rurais em Huambo - Angola (África). Revista Científica Multidisciplinar Núcleo do Conhecimento. Ano 04, Ed. 07, Vol. 13, pp. 0519. Julho de 2019. ISSN: 2448-0959

\section{RESUMO}

Este artigo tem como objetivo, analisar o impacto do sistema educativo nas zonas rurais em Huambo - Angola (África). A educação rural é complexa pois enfrenta várias dificuldades sociais, uma delas é que a maioria da população sobrevive das práticas agrícolas, aqui as crianças abandonam a escola para ajudarem os seus pais no trabalho do campo. Em Angola, a educação rural não possui autonomia pedagógica, e com o despreparo do professor para sustentar essa realidade rural, problematiza o ensino e aprendizagem, pois a escola deve transformar a sociedade ela e o sistema educativo devem estar voltadas as comunidades rurais, respeitando as suas culturas e a tradições, para que a mensagem da escola tenha um retorno.

Palavras-Chave: Sistema educativo, escola, cultura, zona rural, autonomia pedagógica.

${ }^{1}$ Mestrando Em Ciência De Educação E Graduado Em Engenharia Agronômica. 


\section{INTRODUÇÃO}

Olhar ao sistema escolar voltado para as zonas rurais, tem que se viajar das realidades dos centros urbanos a estas zonas rurais no perfil socioeconômico da diversidade cultural, étnica e tradicional dos alunos e das escolas públicas evolventes.

O reflexo desse paradigma emergente é um novo humanismo, que coloca a pessoa, enquanto autor e sujeito do mundo, no centro do conhecimento, mas, tanto a natureza, quanto as estruturas, estão no centro da pessoa ou seja a natureza e a sociedade são antes de tudo humanas. (DAYRELL, 1996, p.2).

Se consideramos a educação como um processo continuo que acompanha, assiste e marca o desenvolvimento do individuo como cidadão e que envolve a preservação e transmissão da herança cultural, rapidamente se deduz a importância que o sistema educativo, em geral, e a escola, em particular. (CARVALHO, 2015)

Uma das principais políticas universais da educação, rebate-se na inclusão social, pois todos têm direito a educação e de serem inseridos no sistema educativo.

Isso porque a educação tem como finalidade promover mudanças desejáveis e estáveis nos indivíduos; mudanças que favoreçam o desenvolvimento integral do Homem e da sociedade.

Para que isso aconteça é necessário programais e politicas que se adequam em cada vertente ou situação indicada, através de uma formação coerente dos docentes, construções de escolas especializadas para cada situação que envolve a comunidade, criar condições que facilitam o feedback entre as instituições escolares e as comunidades rurais, assim como a existência de um programa pedagógico especifico que dá maior autonomia as coordenações pedagógicas locais. 


\section{METODOLOGIA}

Para desenvolver os argumentos deste artigo, o texto se apoia nos pensamentos de muitos autores, por intermédio de documentos como livros, pesquisas em Google acadêmico, artigos publicados em revistas acadêmicas e contou também com a observação social da comunidade rural e com alguns relatos dos professores e das famílias.

\section{O SISTEMA EDUCATIVO E O CONTEXTO SOCIOCULTURAL DAS ZONAS RURAIS}

Com sistema educativo implementado em Angola no ano de 2003, visa a melhoria do ensino e as práticas pedagógicas, o mesmo tem como objetivo a inserção das crianças ao ensino e a alfabetização dos adultos e segundo o INE² - Angola (2014) diz que, Angola tem uma população estimada em 24,3 milhões de habitantes, logo a distribuição dos serviços primários como a educação tem sido um grande desafio, isso porque a maior parte da população angolana vive em zonas rurais.

Segundo ( $\left.\mathrm{LBSE}^{3}, 2001\right)$, a reforma educativa é constituída por vários subsistemas de comprimento obrigatório, sem nenhuma particularidade para os povos habitantes nestas zonas rurais, descartando autonomias pedagógicas já que vive realidades diferentes aos dos centros urbanos. Nas zonas rurais o poder tradicional é predominante, Auschwitz diz que isso trata-se de concentração tradicional da educação, voltada a para a severidade, a repressão do medo e para o caracter manipulador, (ADORNO, 1995), apela sobre o poder para a reflexão, a autodeterminação, a autonomia e a não participação direta do governo na execução dos programas pedagógicos das comunidades. Bourdieu e Passeron (1978), chama isso como uma pedagogia destinada a impor dissimuladamente um duplo arbítrio cultural.

Deparamo-nos com um sistema educativo burocrático, pois perde-se a sensibilidade educacional com relação aqueles que transmitem os conteúdos, neste caso estamos a nos referir do professor que é um dos principais canais de transmissão de 
conhecimento aos alunos e as crianças em particular, nessas zonas. É primordial implementar o discurso de democratização da escola (DAYRELL, 1996, p.2) alhas "são as relações sociais que verdadeiramente educam, isso é, formam, produzem os indivíduos em suas realidades singulares e mais profundas. Nenhum individuo nasce homem...". Todos nós fomos crianças e sabemos as dificuldades de aprender ou formar um pensamento construtivo.

Segundo Morin (2003, p. 93) diz que a "educação serve para transformar o aluno num novo cidadão", mas como será possível transformar a sociedade através da educação se o elemento que esta em constante contato com os alunos não têm autonomias pedagógicas e as didáticas implementadas por eles são muitas vezes limitadas por causa do comprimento obrigatório do programa escolar do sistema educativo, os que constroem as políticas educacionais não têm contato com as crianças da comunidade rural, tudo é elaborado nos gabinetes.

Pois sabemos que a educação tem como um dos seus objetivos instruir os alunos nas mais diversas áreas social através da aquisição de conhecimentos que Ihes permitam transformar o seu comportamento, (DAYRELL. 1994), fala que a escola deve ser um espaço de formação humana ampla e não apenas transmissão de conteúdos voltado a si mesma.

Verificamos que o sistema educativo aplicado pelo governo angolano não se enquadra com o estilo de vida de cada região do país, pois atropela as tradições culturais, as necessidades econômicas e financeiras das famílias que habitam na comunidade rural. Logo a escola deve ser um grande parceiro da comunidade rural e vice-versa, pois a comunidade não pode olhar a escola como uma destruidora dos seus princípios e tradições étnicas ou dos seus padrões de vida. Em Angola e em particular na província do Huambo, são regiões aonde as tradições paternais têm muita influência na vida das crianças, pois os conteúdos transmitidos pelos seus pais ou ancestrais são mais fortes do que ensina a escola. Por um lado esse comportamento ou afinidade que os filhos têm pelos seus pais são importantes, mas quando os seus pais sabem da importância que a escola tem na aquisição de conhecimento e na formação acadêmica dos seus filhos e no caso em que, os seus pais são analfabetos e 
preconceituosos com relação a educação acadêmica ou aqueles pais considerados fanáticos das suas tradições culturais, esses impedem a inserção das crianças nas escolas.

Para aquelas crianças que por outras forças, conseguem ser enquadrados no sistema escolar, muitas das vezes não conseguem permanecer por muito tempo, estando suscetíveis ao abandono escolar por iniciativa dos seus progenitores. Isso porque muitos desses pais dão mais importância as crianças trabalhando ou ajudando-os nos trabalhos de campo (agricultura). E Maia (2011), diz que a escola não pode negar o mundo rural, onde o trabalho constitui um valor, e o trabalho infantil, além de ser uma necessidade, é um valor social, o ensino ministrado nas zonas rurais deve ser apropriado a essa realidade.

É claro e de certo modo justificável que muitas dessas famílias preferem ver seus filhos ajudarem nos trabalhos agrícolas ao envés de estudarem, isso por causa das necessidades financeiras e econômicas que elas atravessam, esquecendo de usar a escola da zona rural como uma agência de mudança. (MAIA, 2011).

Outra preocupação social do sistema educativo vigente nas comunidades rurais são causadas pela evasão escolar e pelos elevados índices de reprovações provocadas pela coincidência das fazes de provas, pois nos inícios e fins de cada ano letivo coincide com as épocas de plantações e colheitas agrícolas e por carência de mão de obras no campo de cultivo muitos dos pais usam as crianças para thes ajudarem na preparação da terra e da sementeira que as vezes é simultânea com as realizações das provas finais e dos trimestres, fazendo com que as crianças faltem aos exames para praticarem agricultura, outro problema que influencia ao abandono escola é a comercialização dos produtos agrícolas por parte das crianças, colocando-as neste caso fora do sistema escolar.

Aqui verificamos uma falta de políticas para reverter esse problema muito grave ao ensino rural, uma vez que as coordenações pedagógicas da escola, não têm autoridade para alterarem o calendário escolar, nem autonomia pedagógica, dependendo somente do Ministério da Educação de Angola que coordena todo 
sistema educativo. Mas se o Ministério da Educação de angola reformar o sistema educativo das zonas rurais como:

1. Paralisação das aulas no período das sementeiras (lavoura), antecipando as férias trimestral;

2. Do mesmo modo atrasando o início das aulas no período das colheitas dos produtos agrícolas;

3. Antecipando os exames finais para em Novembro - Dezembro, as famílias darem continuidade das suas atividades agrícolas.

Desse modo reduziria significativamente o índice do abandono escolar e de reprovações.

O sistema educativo tem ainda que ultrapassar a problemática daquelas famílias numerosas e com um índice de pobreza extrema, das quais as crianças são obrigadas a contribuírem nas despesas de casa principalmente no que tange na procura de mantimentos, têm causado inúmeros abandonos escolar, porque muitas das crianças se deslocarem aos centros urbanos trabalhando como vendedores ambulantes, pedintes na via publica, lavadores de viaturas automóveis e ao anoitecer voltam para suas famílias, alguns mesmos sem conseguirem algo, voltam com as mãos vazias, cansados, desnutridos, desanimados, preocupados com as necessidades que enfrentam em casa, nas comunidades rurais, os meninos são instruídos a serem o chefe de família e a dobrar os seus esforços para trazer mantimento a casa, em alguns casos esses têm mais facilidades de se formarem por causa das futuras responsabilidades como esposo e dele acarretar a dependência econômica dos lares ou casas. (UNESCO, 2010).

Vamos lá, com que animo essas crianças vão escola e se concentrem nas aulas? Infelizmente as nossas escolas rurais não servem merenda escolar, as crianças ficam o dia completo sem se alimentarem, por isso reforçamos dizendo que a educação não deve lutar contra a cultura dos povos das zonas rurais, mas sim respeita-las. 
A cultura é um fator decisivo no funcionamento organizacional. De acordo com Schein (1992), analisado por Carvalho, diz que, a cultura pode ser definida como um padrão de pressupostos básicos, inventados, descobertos ou desenvolvidos por um grupo, à medida que aprendeu a lidar com os seus problemas de adaptação externa e de integração interna, que funcionou bem o suficiente para ser considerado valido. Com isso não vemos a necessidade para desconsiderar o modo de vida das comunidades rurais, temos sim, que adaptar o sistema educativo colmatando os problemas existentes nas escolas rurais e na própria comunidade. A escola e o sistema educativo deve ser mais atrativas para as crianças e para as famílias das comunidades rurais, com ações estratégicas como; distribuição de merenda escolar e recreios com atividades acadêmicas coletivas e individuais com brincadeiras conforme espelha Freire, (1996) pelo menos as crianças iriam a escola para brincar, tomar o pequenoalmoço seriam aproveitadas pelos professores para transmitirem conhecimentos, criando salas de aulas á céu aberto, ai sim muitas dessas crianças teriam mais rendimentos escolares e motivação aos estudos.

Não se pode admitir que em pleno seculo XXI, as políticas do governo angolano quanto ao sistema educativo não esteja voltada as comunidades das zonas rurais sendo essas também cidadãs do mundo. Não se pode estabelecer o mesmo calendário escolar tanto para a zona urbana quanto para a zona rural, o que acaba prejudicando academicamente essas classes populacionais, é necessário que o sistema educativo seja seletivo valorizando o contexto sociocultural das zonas rurais, quando assim não for as crianças continuaram perdidas dentro da escola e consequentemente dentro das salas de aula, a escola frusta as crianças, tanto pelo estômago quanto pela cabeça, uma vez que elas, em geral possuem uma aparência triste e desnutridos, vão à escola em busca de um saber que valorizam: ler, escrever e contar. (MAIA, 2011).

O que ensina o professor nas escolas das grandes cidades é o mesmo que se ensina nas comunidades rurais, esquecendo-se da enorme diferença social entre elas. 


\subsection{O PAPEL DOS PROFESSORES NAS COMUNIDADES RURAIS EM HUAMBO}

Temos aqui também, felicitar alguns heróis que tudo fazem, para que embora com dificuldade fazem funcionar o ensino nas zonas rurais, "professores", são cidadãos que emprestam todo seu saber com patriotismo. Muitos deles deixam as suas casas nas zonas urbanas para se dedicarem a educação rural.

Em Huambo - Angola, os professores acarretam muitas dificuldades de exercerem as suas atividades, eles se deparam com realidades diferentes das que estão acostumadas. Começando com problema de acesso a mesmas zonas, os alojamentos são de condições precárias, enfrentam problemas de água e luz, careciam de meios didáticos, falta de livros e bibliotecas, não existe redes de comunicação, lecionam debaixo das árvores, são mal remunerados, etc. São tantos os problemas que as suas reivindicações não são atendidas pelo governo, uma delas, é o pagamento da de subsídios de periferia estipulado na lei mas não é aplicado, mas nem com isso deixam de cumprir com as suas obrigações.

Por outro lado muitos professores não possuem educação rural pois foram formados nas cidades, Maia, fala desses professores que amiúde apenas uma formação urbana isso quando a têm, ou seguem padrões urbanos que muitas vezes dificultam nas elaborações dos seus programas de ensino, e sem autonomia pedagogia, a situação para eles torna-se mais frustrantes ainda porque os professores rurais trabalham enfrentando todas as adversidades que vão desde as condições das próprias famílias até ao funcionamento precarissimo. (MAIA, 2011).

Também reconhecemos que certos professores carecem de formação contínua para sobrepor as situações que envolvem as comunidades rurais. O professor é uma pessoa que ensina ciência, arte, técnica ou outros conhecimentos e para o exercício dessa profissão, requer-se qualificações acadêmicas e pedagógicas, para que se consiga transmitir/ensinar a matéria de estudo da melhor forma possível ao aluno, o professor deve atualizar-se continuamente isso porque o professor é o espelho da 
sociedade e Freire (1986) faz menção em que o professor tem que possuir a habilidade de ensinar até mesmo com um pequeno gesto.

Os professores devem levar a ânimo leve as pressões exteriores que lhes obrigam a cumprir o programa escolar e olhar para as necessidades interiores dos seus alunos, saber se eles estão aprender os conteúdos ministrados, se há motivação escolar, Maia (2011) descreve que os materiais de ensino-aprendizagem são escassos, não apenas pela falta de recursos financeiros, como também à dificuldades de acesso ao locais aonde poderia ser adquiridos"... limitando-se desse modo as suas didáticas, ainda assim os professores tudo fazem para transformar as crianças socialmente com conhecimentos, Piaget (1974) chama isso de dupla condição de motricidade e de ambiente afetivo favorável para aprendizagem da criança e dos adultos. Analisado por (BASTOS, 2015).

\section{A INSTITUIÇÃO ESCOLAR NAS ZONAS RURAIS}

É sabido que a educação transforma o cidadão e o Homem em si, as escolas nas zonas rurais devem servir de um canal de agregação cultural, fazendo com que as crianças e as famílias valorizarem a ciência associando as tradições socioculturais. Uma vez associando o sistema educativo aos contextos culturais não deverá de modo algum significar desrespeito as tradições étnicas da comunidade mais sim a escola pode ajudar na emancipação cultural e da tradição ancestral, divulgando-as por intermédio do sistema escolar e potencializando-as em diversas disciplinas como a história, geografia, sociologia, etc.

Adorno (1995), pensa que, a medida em que, os ensinamentos da psicologia se aprofunda, todo o caráter, inclusive daqueles que mais tarde praticam crimes formase na primeira infância, a educação tem por objetivo evitar a repetição precisa de se concentrar na primeira infância”, podemos entender que Adorno perspetiva um papel primordial da primeira infância. Se quisermos transformar as comunidades rurais por intermédio das instituições escolares temos que abraçar a sua forma de viver e acima de tudo devemos dar importância na estruturação do seu modo de vida, trabalhando 
com maior empenho na primeira infância para que a educação possa atingir os seus objetivos.

Se o governo investir nestas comunidades rurais, como fez o Brasil, com implementação de indústrias agropecuárias, fazendas e fomentar ao empresariado rural, fará com que essas famílias poderão crescer e desenvolver os seus modos de vida. (MAIA, 2011).

Segundo Szpeleta \& Rockwell (1986), dizem que a instituição escolar seria resultado de um confronto de interesses: de um lado, uma organização oficial do sistema escolar, que "define conteúdos da tarefa central, atribui funções, organiza, separa e hierarquiza o espaço, a fim de diferenciar trabalhos, definindo idealmente, as relações sociais" essas politicas publicas do sistema escolar nas comunidades rurais devem criar uma inter-relação própria, fazendo da escola um processo permanente de construção social, isso porque "cada escola interagem diversos processos sociais: a reprodução das relações sociais, a criação e transformação de conhecimentos, conservação ou destruição da memória coletiva, o controle e a apropriação da instituição, a resistência e a luta contra o poder estabelecido. (SZPELETA \& ROCHWELL, 1986), analisado por (DAYRELL, 1994), aqui trata-se de uma relação em contínua construção de conflitos e negociações em função de circunstâncias determinadas. Neste caso a escola deve servir como a reprodução do velho e a possibilidade da construção do novo dentro da comunidade sem nenhum dos lados considerar uma vitória completa e definitiva, como diz Dayrell ao mesmo tempo que o papel ativo do sujeito, na vida social escolar.

Nas zonas rurais em Huambo - Angola (África) verificamos que a escola não consegue transmitir, nem transformar a comunidade rural e muitas das vezes é vista como uma deturpadora de princípios tradicionais, e sem algum proveito (imediato) para essas populações. Por essas razões e outras não citadas neste artigo é que nos fazem pensar que o sistema educativo vigorado em Angola carece de uma democratização e autonomia pedagógica, aonde o ensino é voltado as caraterísticas socioculturais de cada região angolana como fazem alguns países da América Latina, quanto ao ensino nas zonas indígenas, eles sedem maior autonomia as coordenações 
pedagógicas e aos professores pois reconhecem que são esses que conhecem as fraquezas e os potenciais das crianças e sabem como maneja-las de forma a superar essas fraquezas e tirar proveito das potencialidades que muitas dessas crianças possuem. MORIN (2003, p. 93) diz que "a educação deve contribuir para a auto formação da pessoa (ensinar a assumir a condição humana, ensinar a viver) e ensinar como se tornar cidadão".

Ainda Morin (2003) retrata que os professores devem reconhecer-se na humanidade comum e ao mesmo tempo reconhecer a diversidade cultural inerente a tudo que é humano.

\section{AÇÃO DA COMUNICAÇÃO: ESCOLA VS COMUNIDADE RURAL}

Temos observado que uma das limitações do sistema educativo no contexto cultural das escolas em zonas rurais, muitas das vezes são causadas por erro de comunicação na transmissão das mensagens. A escola deve utilizar uma linguagem que de forma clara possa facilita o intercâmbio, muitas das vezes as comunidades rurais tem-se fechado do mundo contemporâneo, o paradigma da consciência é calçado na ideia de um pensador solitário buscando entender o mundo a sua volta, descobrindo as leis que o governam sozinho. (PINTO, 1995). E por se fechar ao resto do mundo a comunidade rural sente desalojada dentro da sua própria realidade de vida isso porque o meio de comunicação existente nestas comunidades são tradicionais, e a informação demora muito a chegar ao destinatário, causando outros constrangimentos, é necessário que esses povos tomem a consciência por si mesmo através de informações comunicativas que a escola utiliza para transmitir mensagens com uma comunicação curta, clara e eficaz capaz de moldar as várias debilidades de interpretação dos conteúdos ministrados pela escola ou ensino. O povo destas zonas rurais têm balanceado a sua inteligência e seus conhecimentos gerais, por causa da luta a sobrevivência, como Darwin estabeleceu o vinculo entre inteligência e sobrevivência e, que Nietzche e Freud revelaram o inconsciente no âmago da consciência (MCCARTHY, 1984), analisado por (PINTO, 1995) 
É aceitável esse pensamento, em medir a inteligência e a sobrevivência por causa dos seus padrões precários de vida, aonde falta-lhes quase tudo, como dissemos anteriormente, pois as suas principais prioridades são aquisição de mantimentos por intermédio de praticas a agricultura, a caça e a pesca em alguns casos para garantir a sobrevivência das suas famílias, sem ao menos perceberem a mensagem que a escola acarreta para a sociedade rural, infelizmente essa população não tem preocupação em se formar a isso Habermas chama de "teoria crítica da sociedade" (1984, p. 386).

Não quer dizer que descartamos essa teoria crítica da sociedade que Habermas fala, ela é benéfica quando a sociedade em meio rural não possui tabo sobre a escola, há necessidade de reforçar a comunicação entre o sistema escolar e a comunidade rural, reforçando a comunicação linguística e outras. Os atores comunicativos como os professores, devem demostrar a "excelência", da vida no campo, explicando as famílias dos benefícios em se formar e da importância da escola, mas para passar essa mensagem a comunicação precisa ser clara que facilita a interpretações dos conteúdos, sejam elas cultural ou acadêmica exercida simultaneamente entre a escola e a comunidade rural em um mundo objeto, em seu mundo social comum e o seu próprio mundo subjetivo (HABERMAS, 1994), descrito por (PINTO, 1994). Isso porque a mensagem linguística é a mais influente mais atenção, Habermas fala aqui da interpretação, uma comunicação mal interpretada é como se fosse uma arma nas mãos de um soldado pronto a disparar, pois envés de ela transformar a comunidade ela pode até mesmo destruir - la pelas suas próprias mãos.

Habermas (1994), acredita que, “(...) na estrutura da linguagem cotidiana, está embutida uma exigência de racionalidade", pois com a primeira frase proferida, o homem já manifestava uma pretensão de ser compreendido, uma busca de entendimento. (PINTO, 1994).

Habermas distingue três critérios universais da comunicação:

1. Veracidade da afirmação: refere-se a um mundo objeto entendido como a totalidade dos fatos cuja existência pode ser verificada; 
2. Correção normativa: refere-se a um mundo social dos atores, entendido como totalidade das relações interpessoais que são legitimamente regulada;

3. Autenticidade e sinceridade: refere-se a um mundo subjetivo, entendido como a totalidade das experiências do locutor as quais, em cada situação, apenas ele tem acesso privilegiado (HABERMAS, 1994) na análise de Pinto (1994).

Aqui Habermas nos da uma luz, como a comunicação fluir no seio da comunidade, pois ela observar certas diferenciações entre os mundos objetivo, social e subjetivos para que haja interpretações variáveis mais próximas com as relações á realidade social e natural, e que as crenças e valores variam em relação ao mundo objetivo e social. (PINTO, 1994).

Pois a comunicação e a linguagem escolar, devem se adequar com as caraterísticas de cada zona rural e aproximando a escola como membro de suas vidas, adotando as suas culturas isso porque, a cultura é fundamental na criação de uma linguagem categórica conceptuais comuns, que permitam aos membros comunicar eficazmente, como também na definição de critérios de inclusão ou de exclusão do grupo e no estabelecimento de relações de intimidade e amizade. (CHAMBEL E CURRAL, 1998; SCHEIN, 1990,1992)

\section{CONSIDERAÇÕES FINAIS}

O sistema educativo e a sua inter-relação no contexto cultural das zonas rurais é muito fraco, pois carece de várias reflexões na aplicação das políticas funcionais. O sistema educativo precisa de flexibilidade pedagógica, pois as coordenações pedagógicas locais necessitam de autonomia para poderem desdobrar as lacunas enfrentadas no seu cotidiano.

A educação nas zonas rurais é deficitária, deparando de enumeras necessidades, um das quais é a necessidade que as famílias têm de se alimentarem, por essa razão as crianças vão a escola com aparecia triste e desnutridas, por outro lado muitas crianças abandonam a escola para ajudarem os seus pais nos trabalhos agrícolas, reduzindo a mão-de-obra externa. 
Nessas zonas rurais, os professores são considerados heróis porque trabalham arduamente com bastante dificuldades, faltando-os matérias didáticos que thes permitem facilitar a transmissão de conhecimentos. Alguns professores enfrentam dificuldades de alojamento, água e luz outros ainda têm dificuldades de acessos a essas comunidades.

Mas é possível minimizar os efeitos desses constrangimentos, com a aplicação e implementação de autonomia pedagógica, alteração do calendário escolar por causa da época chuvosa, uma vez que a população dedica-se a agricultura.

Criar um canal de mensagem eficiente e eficaz para que os conteúdos ministrados pelos professores possam transformar o modo de vida das crianças e das famílias, respeitando o estilo de vida da comunidade mais concretamente as suas tradições e culturas, é primordial valorizar a vida no campo e profissionalizar os professores, formando-os em educação do campo ou rural.

\section{REFERENCIAS BIBLIOGRÁFICAS}

BASTOS, João Augusto. O diálogo da educação com a tecnologia. Revista educação \& tecnologia 1.1 (2015).

BOURDIEU, P., PASSERON, J. C. A reprodução - elementos para uma teoria do sistema de ensino. Lisboa, Vegas. 1978.

CARVALHO, Renato Gil Gomes. Cultura global e contextos locais: a escola como instituição possuidora de cultura própria. Revista lbero-americana de Educación 39.2 (2006): 5.

CHAMBEL, Maria José, e CURRAL, Luís (1998): psicossociologia da Organização. Lisboa, Texto Editora.

CHEIN, Edgar (1992): Organizational Culture and Leadership, S.Francisco, Jossy Bass. 
CHEIN, Edgar. Organizational Culture, in american Psycologist, vol. 45, 2 pp. 109 119. (2001).

DAYRELL, Juarez Tarcísio. A Educação do aluno trabalhador: uma abordagem alternativa. Educação em Revista, Belo Horizonte 15 (1992): 21-29.

DAYRELL, Juarez. A escola como espaço sócio-cultural. Múltiplos olhares sobre educação e cultura. Belo Horizonte: UFMG (1996): 136-161.

FREIRE, Paulo. Pedagogia da Autonomia: saberes necessários á prática educativa, 25aㅡ Ed. Editora: Paz e Terra, coleção leitura, SP. 1996.

HABERMAS, Jürgen. Teoria de la acción comunicativa: Complementos y estúdios previos. Madri: Catedra, 1994.

https://pt.wikipedia.org/wiki/Professor, acessado 11/08/2017 pelas 12:13.

LBSE. Lei De Bases Do Sistema Educativo. Lei n.ํ 13/01 de Dezembro de 2001. Luanda: Assembleia da República. (2001).

MAIA, Eni Marisa. Educação rural no Brasil: o que mudou em 60 anos? Em aberto 1.9 (2011).

MCCARTHY, Thomas. La teoría crítica de Jürgen Habermas. Madri: Tecnos, 1995.

MORIN, Edgar. A cabeça bem-feita: repensar a reforma, reformar o pensamento / Edgar Morin; tradução Eloá Jacobina. - 8ª ed. -Rio de Janeiro: Bertrand Brasil, 2003.

MORIN, Edgar. Os sete saberes necessários á educação do futuro. Tradução de Catarina Eleonora F. da Silva e Jeanne Sawaya; revisão técnica de Edgar de Assis de Carvalho. 8. ed. São Paulo: Cortez; Brasília, DF: UNESCO, 2003.

PIAGET, Jean. Aprendizagem e Conhecimento. Rio de Janeiro: Freitas Barros, 1974. 
PINTO, José Marcelino de Rezende "Administração e liberdade: um estudo do conselho de escola à luz da teoria da ação comunicativa de Jurgen Habermas. Campinas, Faculdade de Educação/UNICAMP. (tese de doutorado) (1994).

SOUSA, Ângelo Ricardo. A escola por dentro e fora: a cultura da escola e a descentralização financeira, in Revista Ibero-americano de Educação,<http://www.campus-oei.org/revista/fin_edu3.http > [consultada Ago: 2017]

UNESCO, Campanha Mundial pela Educação. www.campaignforeducation.org, acessado aos 11/08/2017 pelas 15:29'. 2010.

Enviado: Maio, 2019.

Aprovado: Julho, 2019. 